Chapter 5

\title{
Helicobacter pylori Infection and Gastric Cancer - Is Eradication Enough to Prevent Gastric Cancer
}

\author{
Aleksandra Sokic-Milutinovic, Dragan Popovic, \\ Tamara Alempijevic, Sanja Dragasevic, \\ Snezana Lukic and Aleksandra Pavlovic-Markovic
}

Additional information is available at the end of the chapter

http://dx.doi.org/10.5772/57412

\section{Introduction}

Helicobacter pylori (H. pylori) is a gram negative, microaerophilic spiral bacterium with a clear role in the pathogenesis of gastric and duodenal ulcer, low grade B cell gastric lymphoma (MALT lymphoma) and gastric cancer. The bacterium was successfully cultivated by Warren and Marshall in 1982. Their discovery led to completely different therapeutic approach to patients with peptic ulcer disease and gastric MALT lymphoma. Despite initial skepticism concerning H. pylori role in gastric carcinogenesis, in 1991 two epidemiological studies [1,2] confirmed previously published reports suggesting higher incidence of gastric cancer in $H$. pylori infected individuals [3-5]. Furthermore, cohort studies in California, Hawaii and Great Britain confirmed increased risk for gastric cancer in $H$. pylori infected individuals. As a result of accumulated scientific evidence Helicobacter pylori was marked as human carcinogen by International Agency for Research on Cancer in 1994. Gastric cancer is the third most common cancer among males and fifth most common among females. The incidence of gastric cancer is declining in developed countries, but the global burden is rising due to cases occurring in developing countries. The five-year survival for advanced stage gastric cancer is below $20 \%$ even in developed countries [6].

Different outcomes of Helicobacter pylori infection are to be expected depending on distinct patterns of gastritis that were identified and described in detail. Namely, antrum-predominant gastritis leads to duodenal ulcer formation while chronic corpus predominant and multifocal atrophic gastritis lead to increased risk for gastric cancer formation [7-9]. 
The outcome of Helicobacter pylori infection depends on characteristics of the microorganism, characteristics of the host and environmental factors.

\section{Helicobacter pylori virulence factors}

Helicobacter pylori virulence depends on different factors enabling it to colonize gastric mucosa and induce tissue damage. Epidemiological studies revealed so far six distinct $H$. pylori strains (hpEurope, hpEastAsia, hpAsia2, hpAfrica 1, hpAfrica2 and hpNEAfrica) that are related to geographic regions and correlate well with the incidence of gastric cancer [10].

$H$. pylori is a highly heterogeneous bacterium [11,12]. Several H. pylori virulence factors are thought to contribute to gastric cancer development and this review will focus on cytotoxinassociated gene A and CagA protein (CagA), vacuolating cytotoxin (VacA) and outer inflammatory protein (OipA) (Figure 1) with a brief comment on possible role of duodenal ulcerpromoting gene (dupA).

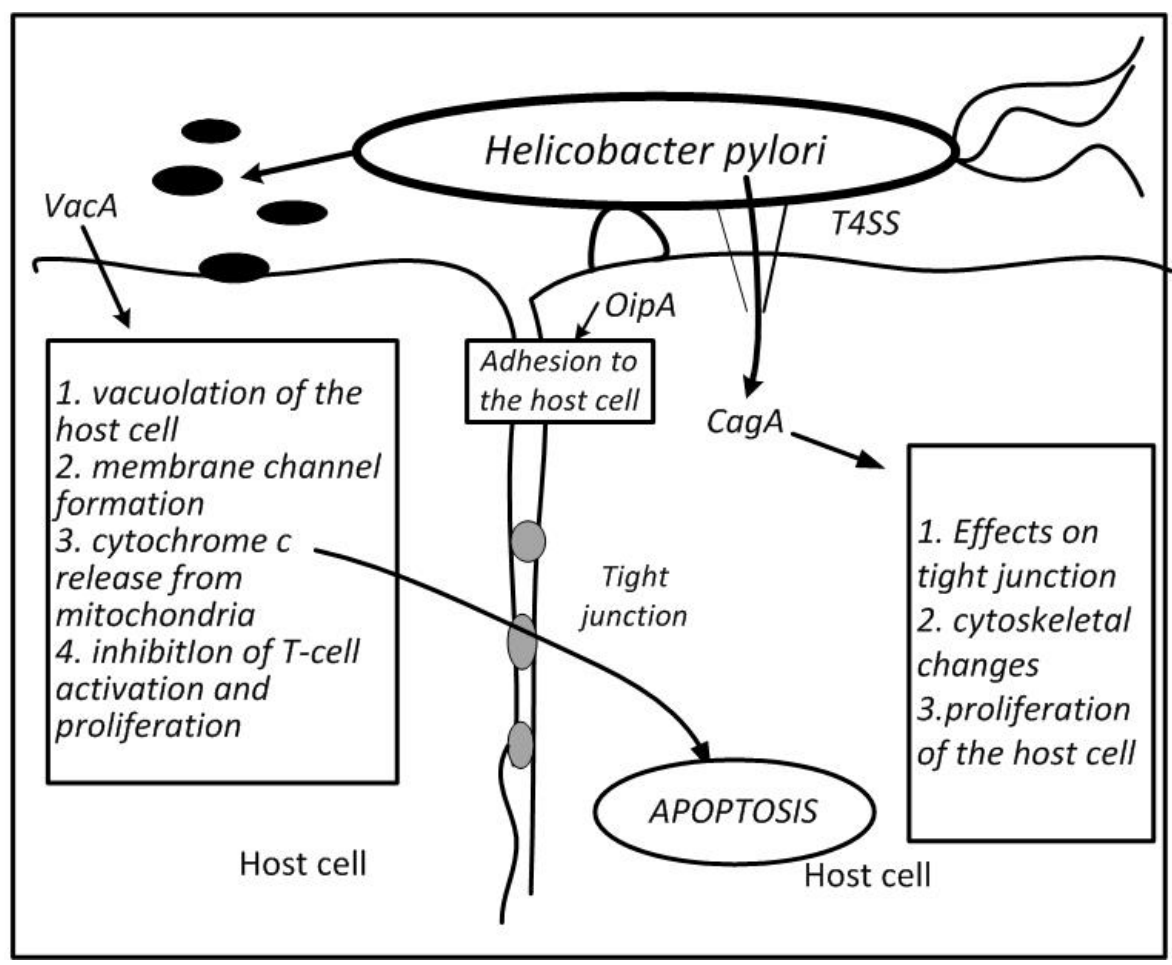

Figure 1. Mechanism of Helicobacter pylori induced host cell injury 


\section{1. $\operatorname{cag} A$}

There are two types of clinical H. pylori isolate: CagA-producing (cagA positive) strains and CagA-nonproducing (cagA negative) strains. Results of studies obtained on animal model revealed that gastric cancer developed only in animals infected with cagA positive $H$. pylori strains or when CagA protein was artificially introduced into the host $[13,14]$ and authors concluded that CagA protein was important factor in gastric carcinogenesis. Further investigations revealed that $c a g A$ gene polymorphisms could at least partly explain why only some $\operatorname{cag} A$ positive individuals develop gastric cancer. Namely, there are different number of repeat sequences located on 3' region of the cagA gene in different $H$. pylori strains. It is now well known that sequences of these repeat regions differ significantly between strains isolated in East Asia and Western strains [15]. Each repeat region of the CagA protein contains Glu-ProIle-Tyr-Ala (EPIYA) motifs. The first repeat region is termed EPIYA-A and EPIYA-B and second repeat region EPIYA-C or EPIYA-D segments [11]. Western type CagA has EPIYA ABC, ABCC or ABCCC, while East Asian CagA has EPIYA ABD segments [11].

CagA protein is composed of a disordered C-terminal region that contains the EPIYA motifs and a structured $\mathrm{N}$-terminal region with several conserved regions. When the bacterium contacts the host cell CagA is injected into the host cell via the cag pathogenicity island (cagPAI)-encoded type IV secretion system (T4SS). Upon injection, CagA is linked to the inner leaflet of the cell membrane probably via an electrostatic interaction with phosphatidylserine [16]. When injected into the cytoplasm via the T4SS, CagA can be phosphorylated by the host and alter host cell signaling in both phosphorylation-dependent and phosphorylation-independent manner. CagA is phosphorylated on EPIYA motifs [17]. Induction of heme oxygenase 1, which exhibits antiinflammatory and antioxidant effects, reduced CagA phosphorylation during H. pylori infection of gastric epithelial cells in vitro. However, there is data suggesting that the bacterium developed a strategy to diminish hemeoxygenase 1 geneexpression in gastricepithelial cells [18].

Recently it was demonstrated that another protein component of T4SS termed CagL induces hypergastrinemia, which is a major risk factor for the development of gastric adenocarcinoma [17].

\section{2. vacA}

VacA induces vacuolation of the host cell, membrane-channel formation, cytochrome $c$ release from mitochondria leading to apoptosis, induces autophagy and alters host immune response $[17,20,21]$. VacA also inhibits T-cell activation and proliferation [22]. All H. pylori strains have a functional $v a c A$ gene. There is a variation in the vacuolating activity among different $H$. pylori strains [23] related to differences in the vacA gene structure at the signal (s1 and s2) region, middle region ( $\mathrm{m} 1$ and $\mathrm{m} 2$ ) and intermediate (i1 and $\mathrm{i} 2$ ) region. Combination of subtype of these three regions influences the levels of VacA activity and is related to risks for different gastrointestinal diseases.

The most cytotoxic are s1/m1 strains, followed by s1/m2 strains, whereas s $2 / \mathrm{m} 2$ strains have no cytotoxic activity and s2/m1 strains are rare [24]. Individuals infected with s1 or $\mathrm{m} 1 \mathrm{H}$. pylori strains have an increased risk of peptic ulcer or gastric cancer compared with individuals 
infected with s2 or m2 strains [11]. In East Asia most H. pylori strains are s1 type that led to conclusion (based on epidemiological data) that in East Asia presence of $\mathrm{m} 1$ region leads to increased risk for gastric cancer [11] and its typing is the best marker for gastric cancer risk out of all vacA regions.

Intermediate region of $v a c A$ is identified between $\mathrm{s}$ and $\mathrm{m}$ regions few years ago. All s1/m1 strains belong to the type i1, and all s $2 / \mathrm{m} 2$ strains are type i2. Strains tha contain $\mathrm{s} 1 / \mathrm{m} 2$ can be type i1 or i2. Strains with i1 region are more pathogenic. In some populations typing of i-region is superior in predicting gastric cancer risk than typing of $s$ region, while in other populations it has no predictive value [25].

The deletion ( $d$ ) region-was identified between the i-region and the $\mathrm{m}$ region [26]. The $\mathrm{d}$ region is divided into $\mathrm{d} 1$ and $\mathrm{d} 2$. The study of Western strains demonstrated that $\mathrm{d} 1$ was a risk factor for gastric mucosal atrophy; however, almost all East Asian strains are classified as $\mathrm{s} 1 / \mathrm{i} 1 / \mathrm{d} 1[11]$.

\section{3. oipA}

Outer membrane proteins (OMPs) are coded by different genes in Helicobacter pylori genome. One of the OMPs that can function as adhesin is OipA, which was identified in 2000 [11].

OipA is a protein that induces proinflammatory response and its activity leads to increase in mucosal interleukin-8 (IL8) levels. OipA is involved in the attachment of $H$. pylori to gastric epithelial cells in vitro [27]. Results from animal studies demonstrated that OipA alone plays a role in the development of gastric cancer [13].

The production of CagA, VacA and OipA is linked and the majority of H. pylori strains produce either all of these proteins or none of them. Almost all East Asian strains of H. pylori are classified as CagA-producing, VacA-producing (vacA s1), and OipA-producing strains and are highly pathogenic. In addition, CagA, VacA and OipA are all thought to be involved in the development of both gastric cancer and duodenal ulcer [11].

\section{4. $\operatorname{dupA}$}

Duodenal ulcer-promoting gene $\operatorname{dupA}$ was described in 2005. It is localized in the plasticity zone and it is involved in T4SS formation. Initial report suggested it to be the first diseasespecific $H$. pylori virulence factor that induced duodenal ulcer formation and had a suppressive action on gastric cancer (DupA) [28]. After this report multiple studies failed to demonstrate correlation between $d u p A$ gene and specific gastroduodenal disease $[10,29,30]$. This gene is,however, highly polymorphic, and that could explain the conflicting data obtained in different studies [17].

\subsection{Geographic differences in gastric cancer incidence related to Helicobacter pylori strains}

Multilocus sequence typing (MLST) of the housekeeping genes revealed six H. pylori strains (hpEurope, hpEastAsia, hpAsia2, hpAfrica 1, hpAfrica2 and hpNEAfrica) that are related to geographic regions and correlate well with the incidence of gastric cancer. 
Sequence differences among the examined housekeeping genes of the six major genotypes probably have no influence on the disease outcome but serve as a marker for other virulence factors related to the disease outcome (i.e cag $A$ and $v a c A$ ) [10]. In 2003, Falush et al analyzed 370 H. pylori isolates and assigned the strains to four main clusters: hpEurope, hpEastAsia, hpAfrica1 and hpAfrica2 due to their obvious geographical associations [31]. HpEurope is common in Europe and countries colonized by Europeans and most isolates from East Asia belong to hpEastAsia. HpAfrica2 is very distinct and has only been isolated in South Africa. Four years later Linz et al expanded the analysis using $769 \mathrm{H}$. pylori isolates and assigned the isolates to six distinct groups, adding to previously descried clusters (hpEurope, hpEastAsia, hpAfrica1 and hpAfrica2) two new clusters termed hpAsia 2 and hpNEAfrica. Cluster hpAsia2 was isolated in South and Southeast Asia. Cluster hpNEAfrica is predominant among isolates from Northeast Africa [12].

Populations with high rates of gastric cancer correspond with regions presenting hpEastAsia strains. In contrast, incidence of gastric cancer is very low in Africa, where most strains are hpNEAfrica, hpAfrica1 or hpAfrica2, and in South Asia, where most strains are hpAsia2. The differences in $H$. pylori isolates in different populations are considered to be an explanation of the both African and Asian enigma. Namely, populations with high incidences of Helicobacter pylori infection in East Asian countries have high incidences of gastric cancer, as opposed to low incidence of gastric cancer in other highly infected populations in Africa (African enigma) and South Asia (Asian enigma) [10].

\section{Host factors}

Host characteristics and immune response to Helicobacter pylori infection also play a role in gastric carcinogenesis. Different gene polymorphisms that affect host immune response and extent of cell proliferation are described and linked to gastric carcinogenesis together with gene polymorphisms for growth factors and growth factor receptors. Majority of these polymorphisms are single nucleotide polymorphisms (SNP). In recent years, host genetic polymorphisms involved in inflammatory response, carcinogen metabolism, antioxidant protection, mucosal protection and cell proliferation regulation have been widely studied as potential biomarkers to predict gastric cancer risk.

\section{Cytokine gene polymorphisms}

Cytokines modulate inflammatory response to Helicobacter pylori infection and indirectly the risk for gastric cancer. Gene polymorphisms for interleukin-1 beta and its receptor antagonist, tumor necrosis factor alpha, interleukin- 8 and interleukin-10 were extensively studied and reported as relevant in determining gastric cancer risk. 


\subsection{Interleukin-1}

Interleukin-1 beta (IL-1 $\beta$ ) is a potent inhibitor of gastric acid secretion. Reduced gastric acid secretion on the other hand promotes development of $H$. pylori induced pangastritis, gastric mucosa atrophy and subsequently, in a subset of individuals, gastric cancer development. ElOmar et al described in 2000 polymorphisms in the pro-inflammatory IL-1B gene (encoding IL-1 $\beta$ ) and IL-IRN (encoding IL-1 $\beta$ receptor antagonist) associated with elevated risk for hypochlorhydria and gastric cancer in the persons with $H$. pylori infection [32] (El-Omar). Presence of $I L-1 B-31 C$ or $-511 \mathrm{~T}$ and $I L-I R N^{*} 2 /{ }^{*} 2$ polymorphisms is associated with a $2-3$-fold increase in risk for intestinal and diffuse non-cardia gastric cancer among $H$. pylori-infected persons [33]. These genetic polymorphisms modulate gastric cancer risk by increasing expression of pro-inflammatory cytokine IL-1 $\beta$. It was later established that these polymorphisms interact synergistically with bacterial virulence factors (cag $A$ positive, vac $A$ s1 and vac $A$ $\mathrm{m} 1)$. Gastric cancer risk is highest among those with both host and bacterial high-risk genotypes [34].

Results of meta-analysis provided by Persson et al. based on available data from epidemiological studies showed strongest association of IL1RN2 polymorphism with increased risk for gastric cancer [35] in non-Asian populations for both intestinal and diffuse cancers. The IL1RN22 genotype has been reported to cause high circulating IL-1receptor antagonist and IL-1 $\beta$ levels resulting in a severe and prolonged inflammatory response. IL1B-511T carriers were found to have an increased risk of gastric cancer in non-Asian populations. Possible explanation is that stronger inflammatory reaction may increase the risk of cancer through damage to gastric cells and bacterial overgrowth and accumulation of toxic byproducts [32]. These findings are supported by results of some [36,37], but not all previously published metaanalysis [38]. Surprisingly, according to Persson et al IL-1B-31C polymorphism was associated with a reduced overall risk for gastric cancer in Asian populations [35].

\subsection{Tumor necrosis factor alpha}

Tumor necrosis factor alpha (TNF- $\alpha$ ) is another proinflammatory cytokine produced in gastric mucosa in response to $H$. pylori infection. Polymorphisms in TNF-A gene, especially presence of the high producing A allele of TNF- $A$ at position $308(\mathrm{G} \rightarrow \mathrm{A})$ is considered to be associated with increased risk for non-cardia gastric cancer [6]. This finding is supported by majority [39-41], but not all of available meta-analysis [35].

\subsection{Interleukin 10}

Interleukin 10 is an anti-inflammatory cytokine that down-regulates $I L-1 B, T N F-A$, and interferon- $\gamma$ gene expression. Previously published studies suggested that individuals carrying the IL-10 ATA haplotype associated with low IL-10 production $(-592,-819,-1082)$ have an increased risk for non-cardia gastric cancer [33]. Nevertheless meta-analysis failed to confirm these observations except for IL10-1082G where the effect of polymorphism depends on ethnicity of the host. It seems that this polymorphism increases gastric cancer risk in Asians, but has no significant effect in non-Asian populations [39]. 


\subsection{Interleukin 8}

IL-8 is a CXC family cytokine that is a potent chemoattractant for neutrophils and lymphocytes affecting proliferation, migration, and tumor angiogenesis. However, not all studies have replicated the positive associations between pro-inflammatory cytokines polymorphisms and gastric cancer risk [42]. A polymorphisms in $I L-8(-251 \mathrm{~T} \rightarrow \mathrm{A})$ is associated with increased production of IL-8 in H. pylori infected gastric mucosa and with precancerous gastric abnormalities in Caucasians and gastric cancer in Asian populations [43]. Nevertheless, studies in Asian populations $[44,45]$ have failed to confirm relevance of this polymorphism and metaanalysis supported this finding [35], but this can be attributable to small sample size in these studies and limited number of the high quality studies available for the meta-analysis.

\subsection{Presence of multiple high-risk cytokine gene polymorphisms}

Possession of multiple high-risk host polymorphisms is associated with increased risk for gastric cancer. Presence of 3-4 of the polymorphisms $\left(I L-B 1-511^{*} \mathrm{~T}, I L-I R N^{*} 2{ }^{*} 2, T N F-A-308^{*} \mathrm{~A}\right.$ and IL-10 ATA/ATA) confers a 27-fold increase in risk of non-cardia gastric cancer [33].

\section{Polymorphisms in innate immune response genes}

H. pylori attaches to gastric epithelium via receptors. Thus, polymorphisms in the innate immune response genes, which interact with these receptors, could influence outcome of infection and potentially the risk of gastric cancer.

\subsection{Toll like receptor 4 (TLR4)}

TLR4 is a cell-surface signaling receptor involved in the recognition and host response to Helicobacter pylori. Toll-like receptor 4 gene codes for a lipopolysaccharide (LPS) receptor molecule involved in innate immune recognition of microbe pathogen-associated molecular patterns. The TLR4+896A>G polymorphism linked with impaired reactivity to bacterial lipopolysaccharide may play a role in gastric carcinogenesis [44] and is associtaed with hypochlorhydria and upper gastrointestinal cancer. TLR4 896 polymorphisms results in changed conformation of the extra cellular domain of the TLR4 receptor and carriers are unable to adequately respond to LPS challenge. The defective signaling through TLR4 leads to an exaggerated inflammatory response with severe tissue destruction that causes gastric atrophy and severe hypochlorhydria. Two independent case-control studies have demonstrated that TLR4+896G carriers have eightfold increase in odds ratio for hypochlorhydria and gastric atrophy, and over two-fold increase for gastric cancer $[44,45]$

\section{Cell proliferation-related gene polymorphisms}

Meta-analysis by Gao et al identified 23 polymorphisms significantly related to gastric cancer in at least one published study suggesting the importance of polymorphisms in genes 
implicated in cell proliferation in development of gastric cancer. The overall effect of these polymorphisms is probably modest but should not be neglected [46].

\subsection{Cell cycle and apoptosis regulators}

Cell cycle and apoptosis regulators are directly involved in the initiation of malignant proliferation of the cell. Polymorphisms of functional regulators of TP53, TP53BP2 (tumor protein P53 binding protein 2) and MDM2 (gene encoding Mouse double minute 2 homolog, an important negative regulator of the p53 tumor suppressor) were found to be related to the development of gastric cancer. TP3 gene encodes a multi-purpose protein (P53) that takes part in regulating the cell cycle, carrying out programmed cell death, initiating DNA repair, and regulating the transcription of a large number of genes that cells use for various biological purposes. Given its many essential functions, P53 is frequently found inactivated in tumor cells. Results of meta-analysis confirm that association of TP3 gene polymorphisms vary by population and type of gastric cancer. The TP3 Arg allele carriers of Asian origin have an increased risk for gastric cancer, while same polymorphism seems to have protective effects in Caucasians [43]. Possible explanation is difference in environmental factors that act together with either apoptotic or DNA repairing mechanisms. Data obtained for other two polymorphisms in cell-cycle related genes that were extensively studied are inconsistent, both for Lmyc (nuclear oncogen) EcoRI polymorphism and p21 (gene encoding P21/ cyclin-dependent kinase inhibitor 1) polymorphism (Arg31Ser), probably due to relatively small sample sizes and underestimated importance of environmental factors and their interplay with host genetics.

PPAR- $\gamma$ (peroxisome proliferator-activated receptors $\gamma$ ) is a member of the nuclear hormone receptor family that plays an important role in cell differentiation and regulation of metabolism. A potential interplay between $P P A R-\gamma$ Pro12Ala polymorphism and $H$. pylori infection was observed in the development of gastric cancer $[47,48]$.

\subsection{Growth factors and growth factor receptors}

Polymorphisms determining higher level of growth factors and related receptors, which are important for tissue repair, were associated with reduced risk of gastric cancer. Such associations were observed for gene encoding epidermal growth factor (EGF) EGF 5' UTR 61G>A, [49], polymorphisms for transforming growth factor beta (TGFB) i.e. TGFB1 $-509 \mathrm{C}>\mathrm{T}$, TGFBR2-875G $>\mathrm{A}[50]$ and gene encoding insulin-like growth factor-binding protein 3 IGFBP3 $-202 \mathrm{~A}>\mathrm{C}$ and Gly32Ala [51,52].

\section{Environmental factors}

Environmental regulation of virulence factors could be an interesting concept explaining why not all infected individuals develop severe complications of disease despite infection with pathogenic Helicobacter pylori strains.

Recent study demonstrated that high salt diet could influence H. pylori protein expression [53]. 


\subsection{Diet}

In 2007 World Cancer Research Fund declared that high intake of vegetables and fruit probably decrease risk of gastric cancer, and that high intakes of salt and salty food probably increase risk of gastric cancer [54]. The proposed underlying mechanism for the inverse association of gastric cancer risk with vegetable and fruit/rich diet is related to the presence of antioxidants. Salt on the other hand acts directly on the stomach lining, destroying the mucosal barrier, causes gastritis and increased epithelial cell proliferation [55]. A synergistic interaction between diet and Helicobacter pylori infection with risk of gastric cancer has been proposed [56]. Recent study demonstrated that high salt diet could influence Helicobacter pylori protein expression leading to increased risk of gastric cancer [53]. Salt responsive increase in cag $A$ expression attributable to increased CagA transcription was described that could lead to increased risk of gastric cancer.

\subsection{Smoking}

Tobacco smoking is the risk factor associated with the largest number of cancer cases worldwide and the causal link with stomach cancer is recognized [54]. A recent meta-analysis found significant positive associations of smoking with risk of both cardia and non-cardia gastric cancer among the majority of studies, overall increasing risk by $62 \%$ for male and $20 \%$ for female current smokers [57]. It is possible that tobacco smoke carcinogens affect gastric cancer risk directly through contact with the stomach mucosa or indirectly through the blood flow [54]. In a large population-based study in Europe (EPIC), 17.6\% of gastric cancer cases were attributed to smoking [56]. The cancer risk in past smokers can remain up to 14 years after cessation of smoking $[57,58]$. The effect of smoking on gastric cancer is dose-dependent and additive in the presence of other risk factors [59,60]. However, passive smoking does not seem to increase the risk [61].

\subsection{Non-steroidal anti-inflammatory drugs}

Protective effect of regular use of non-steroidal anti-inflammatory drugs (NSAIDs) and particularly aspirin on risk of gastric cancer was repeatedly reported in observational studies and then results of meta-analysis [62] confirmed these finding. According to Algra et al regular NSAID users have up to $20 \%$ reduced risk of gastric cardia adenocarcinoma and up to $36 \%$ reduced risk of distal gastric adenocarcinoma [62]. NSAIDs suppress the production of cyclooxygenase enzymes. Data on clinical efficacy of NSAIDs in prevention of gastric cancer first suggested that aspirin reduces risk for both proximal and distal gastric cancer [63]. Recent results from population-based intervention trial by Wong et al revealed that celecoxib treatment or Helicobacter pylori eradication alone had beneficial effects on the regression of advanced gastric lesions. Nevertheless no favourable effects were seen for $\mathrm{H}$. pylori eradication followed by celecoxib treatment [64]. Meta-analysis by Tian et al suggests significant protective effects of NSAIDs against gastric cancer [65]. 


\subsection{Socioeconomic status}

Lower socioeconomic status is associated with at least two-fold greater risk of gastric cancer irrespective of the country incidence of gastric cancer [54]. Possible explanation is related to increased likelihood of transmission and re-infection with $H$. pylori (large family, poor sanitation, less frequent use of antibiotics). Also, low socioeconomic status is related to a diet lower in fresh fruits and vegetables.

\section{Importance of Helicobacter pylori eradication in prevention of gastric cancer development-current knowledge and evidence}

Helicobacter pylori infection is mainly associated with distal forms and intestinal-type gastric carcinoma [7-9]. Namely, there are two distinct sites of gastric adenocarcinoma: proximal (cardia) and distal (non-cardia), with different epidemiological and clinical characteristics. Main risk factors for cardia gastric cancer are obesity, gastro-oesophageal reflux disease and Barrett's oesophagus [66] and its incidence is increasing over last decades. On the contrary, main risk factors for development of distal gastric cancer are H.pylori, low socioeconomic status, smoking, salty and smoked food intake, low consumption of fruits and vegetables and a family history of gastric cancer. Clear decline in incidence of distal gastric cancer is observed in the last decades [67].

Histologically gastric cancer is, according to Lauren classification, divided into two subtypes: intestinal and diffuse type. The intestinal type is related to corpus-predominant gastritis with intestinal metaplasia and is closely related to long-lasting H.pylori infection, whereas the diffuse originates from superficial pangastritis without atrophy [7-9].

Intestinal type gastric adenocarcinoma results from a prolonged precancerous process. The link between gastric intestinal metaplasia and cancer was proposed by pathologists in Java and Sumatra in 1938. This idea was over time only occasionally revisited by scientists until in 1975 Correa et al proposed a model of gastric carcinogenesis. This model postulated that intestinal type of gastric cancer was a result of progressive changes in the gastric mucosa [68]. Authors updated their model in 1988 and 1992. In Correa cascade the following consecutive steps are now recognized: normal gastric mucosa, superficial (non-atrophic) gastritis, multifocal atrophic gastritis (MAG), complete (small intestine type) intestinal metaplasia followed by intestinal metaplasia of the incomplete (colonic) type, low-grade dysplasia, high-grade dysplasia and invasive adenocarcinoma. [7-9, 68]. Loss of normal glandular tissue is the first specific recognizable step in the precancerous cascade. However, the changes of the precancerous lesions over time remain an issue difficult to assess leading to the fact that the point of no return, although of critical importance for timely eradication, still remains unidentified.

Five randomized controlled trials (RCT) reported effects of H.pylori infection eradication on invasive gastric cancer or premalignant histological lesions of gastric mucosa. [69-75]

Study by Wong et al. was designed as RCT conducted in a high-risk gastric cancer region in China that evaluated gastric cancer incidence as a primary outcome [69]. Authors identified 
healthy individuals with $H$. pylori infection and treated them either with eradication therapy or placebo. During a follow-up period of 7.5 years authors failed to demonstrate overall decrease in gastric cancer incidence. The study concluded that incidence of gastric cancer development in the general population was similar between subjects receiving $H$. pylori treatment and placebo. The study, however, suggested the possible protective role of $H$. pylori eradication in participants without precancerous lesions, including gastric atrophy, intestinal metaplasia, or dysplasia.

Other above cited trials were not designed to assess gastric cancer as a primary outcome [70, $71]$ or had low numbers of gastric cancer cases $[69,72]$ to provide an informative assessment of the effects of eradication on cancer occurrence. Nevertheless, recently an important study was published by Ma et al [74] with the long-term follow-up results of a randomized trial in which $2258 \mathrm{H}$. pylori seropositive adults from a general population in China were randomly assigned to three interventions ( $H$. pylori eradication, garlic supplements, supplemental vitamins) or control groups. After 15 years there were 34 new gastric cancers in $H$. pylori eradication group and 52 in the corresponding control group (relative risk of $0.61,95 \%$ confidence interval $0.38-0.96$ ) that clearly demonstrated benefit of eradication therapy in gastric cancer prevention.

This year Lee et al [76] evaluated the benefit of mass eradication of H. pylori infection started in Taiwanese population with high incidence of $H$. pylori infection. Individuals who were aged 30 years and older were tested for the presence of $H$. pylori infection and those positive underwent endoscopic screening and subsequent eradication therapy. Authors demonstrated the success of eradication in $78.7 \%$. Gastric atrophy incidence decreased in over $77 \%$ after successful eradication of $H$. pylori with no significant change in intestinal metaplasia. Gastric cancer incidence during the chemoprevention period was reduced by $25 \%$. Based on these findings authors suggest that ultimate benefit in reducing gastric cancer incidence and its mortality should be validated by a further long-term follow-up.

Over a decade ago Uemura et al. [77] first reported that H. pylori eradication could reduce the subsequent development of metachronous gastric cancer after endoscopic resection of early gastric carcinoma. Namely, 132 H. pylori serology-positive patients who underwent endoscopic resection were assigned to the $H$. pylori-treatment group or the no treatment group according to the patients' preference. Regular endoscopic follow-up for up to 4 years found no metachronous cancer in $H$. pylori-treated patients compared to $9 \%$ in the no treatment group.

Some years later, Fukase et al. [75] reported the results of a trial in which more than five hundred patients in Japan who had previously undergone endoscopic resection for treatment of early gastric cancer were randomized to either $H$. pylori eradication or usual care. They demonstrated statistically significant $65 \%$ reduction in the risk of metachronous gastric carcinoma compared with the control group.

The evidence from more recent trial reports [74-76], taken together with the epidemiological and experimental evidence for the carcinogenic activity of chronic $H$. pylori infection, provides support for a protective effect of $H$. pylori eradication in gastric cancer. 


\section{Conclusion}

H. pylori infection contributes 5.5\% to global cancer burden and is the single most important cause of infection-associated cancer globally [6]. It is therefore reasonable to consider eradication therapy as optimal preventive approach in infected individuals. Interrupting transmission of infection is primary prevention, secondary should be eradication therapy and tertiary prevention includes identification of the individuals with early gastric cancer. However data from large study in China that included 1630 healthy carriers of $H$. pylori infection that were given eradication therapy or placebo detected no difference of gastric cancer incidence between these two groups [69]. Benefit would probably be seen in patients where gastric cancer cascade did not cross the point of no return, which would explain results of recently published studies [74,76]. Namely, intestinal-type gastric cancer results from a multistep process of mucosal alterations leading from chronic inflammation (gastritis) to glandular atrophy followed by development of intestinal metaplasia and dysplasia resulting in invasive carcinoma. Clinical studies should aim to identify a 'point of no return', a situation when mucosal alterations are no longer reversible after $H$. pylori eradication and progression to gastric cancer became independent of presence of the bacterium.

Higher risk for gastric cancer might be modulated by an overall pro-inflammatory host genetic profile in the adaptive and innate immune systems genes (e.g. IL-1B, TNFA, IL-10, IL-8, and TLR4) [77]. This pro-inflammatory profile might drive the immune response to $H$. pylori infection to a severe chronic inflammatory phenotype, reduced gastric acid secretion, bacterial overgrowth, and oxidative stress to the gastric mucosa.

Therefore timely eradication of $H$ pylori infection especially in individuals with proinflammatory genetic profile could prevent development and in long term possibly decrease incidence of gastric cancer.

\section{Author details}

Aleksandra Sokic-Milutinovic ${ }^{1,2}$, Dragan Popovic ${ }^{1,2}$, Tamara Alempijevic ${ }^{1,2}$, Sanja Dragasevic ${ }^{2}$, Snezana Lukic ${ }^{1,2}$ and Aleksandra Pavlovic-Markovic ${ }^{1,2}$

1 School of Medicine, University of Belgrade, Belgrade, Serbia

2 Clinic for Gastroenterology and Hepatology, Clinical center of Serbia, Belgrade, Serbia

\section{References}

[1] Talley NJ, Zinsmeister AR, Weaver A, DiMagno EP, Carpenter HA, Perez-Perez GI, Blaser MJ. Gastric adenocarcinoma and Helicobacter pylori infection. J Natl Cancer Inst 1991;83(23):1734-1739 
[2] Parsonnet J, Friedman GD, Vandersteen DP, Chang Y, Vogelman JH, Orentreich N, Sibley RK. Helicobacter pylori infection and the risk of gastric carcinoma.N Engl J Med 1991;325(16):1127-1131.

[3] Scott N, Lansdown M, Diament R, Rathbone B, Murday V, Wyatt JI, McMahon M, Dixon MF, Quirke P. Helicobacter gastritis and intestinal metaplasia in a gastric cancer family. Lancet 1990;335(8691):728.

[4] Marwick C. Helicobacter: new name, new hypothesis involving type of gastric cancer. JAMA 1990;264(21):2724-2727.

[5] Caruso ML, Fucci L. Histological identification of Helicobacter pylori in early and advanced gastric cancer.J Clin Gastroenterol 1990;12(5):601-602.

[6] Mbulaiteye SM, Hisada M, El-Omar EM Helicobacter pylori associated global gastric cancer burden. Front Biosci (Landmark Ed). 2009;14:1490-1504.

[7] Correa P. A human model of gastric carcinogenesis. Cancer Res 1988; 48: 3554-3360.

[8] Correa P. Human gastric carcinogenesis: a multistep and multifactorial process First American Cancer Society Award lecture on cancer epidemiology and prevention. Cancer Res 1992; 52: 6735-6740.

[9] Correa P, Piazzuelo MB. The gastric precancerous cascade. J Dig Dis 2012;13:2-9.

[10] Yamaoka Y, Kato M, Asaka M. Geographic differences in gastric cancer incidence can be explained by differences between Helicobacter pylori strains. Intern Med. 2008;47(12):1077-1083

[11] Yamaoka Y. Mechanisms of disease: Helicobacter pylori virulence factors. Nat Rev Gastroenterol Hepatol. 2010;7(11):629-641.

[12] Linz B, Balloux F, Moodley Y, Manica A, Liu H, Roumagnac P, Falush D, Stamer C, Prugnolle F, van der Merwe SW, Yamaoka Y, Graham DY, Perez-Trallero E, Wadstrom T, Suerbaum S, Achtman M.An African origin for the intimate association between humans and Helicobacter pylori. Nature 2007;445:915-918

[13] Franco AT, Johnston E, Krishna U, Yamaoka Y, Israel DA, Nagy TA, Wroblewski LE, Piazuelo MB, Correa P, Peek RM Jr. Regulation of gastric carcinogenesis by Helicobacter pylori virulence factors. Cancer Res 2008;68:379-387

[14] Ohnishi N, Yuasa H, Tanaka S, Sawa H, Miura M, Matsui A, Higashi H, Musashi M, Iwabuchi K, Suzuki M, Yamada G, Azuma T, Hatakeyama M.Transgenic expression of Helicobacter pylori CagA induces gastrointestinal and hematopoietic neoplasms in mouse. Proc Natl Acad Sci USA 2008;105:1003-1008.

[15] Yamaoka Y, Osato MS, Sepulveda AR, Gutierrez O, Figura N, Kim JG, Kodama T, Kashima K, Graham DY. Molecular epidemiology of Helicobacter pylori: separation of H. pylori from East Asian and non-Asian countries. Epidemiol Infect 2000;124:91-96. 
[16] Hayashi T, Senda M, Morohashi H, Higashi H, Horio M, Kashiba Y, et al. Tertiary structure-function analysis reveals the pathogenic signaling potentiation mechanism of Helicobacter pylori oncogenic effector CagA. Cell Host Microbe 2012;12:20-33.

[17] Cid TP, Fernández MC, Benito Martínez S, Jones NL. Pathogenesis of Helicobacter pylori Infection. Helicobacter 2013;18 Suppl 1:12-17

[18] Gobert AP, Verriere T, de Sablet T, Peek RM Jr, Chaturvedi R, Wilson KT. Haem oxygenase-1 inhibits phosphorylation of the Helicobacter pylori oncoprotein CagA in gastric epithelial cells. Cell Microbiol 2013;15:145-156.

[19] Wiedemann T, Hofbaur S, Tegtmeyer N, Huber S, Sewald N, Wessler S, Backert S, Rieder G. Helicobacter pylori CagL dependent induction of gastrin expression via a novel alphavbeta5-integrin-integrin linked kinase signalling complex. Gut 2012;61:986-996.

[20] Atherton JC. The pathogenesis of Helicobacter pylori-induced gastro-duodenal diseases. Annu Rev Pathol Mech Dis 2006;1:63-96.

[21] Cover TL, Blanke SR. Helicobacter pylori VacA, a paradigm for toxin multifunctionality. Nat Rev Microbiol 2005;3:320-332

[22] Gebert B, Fischer W, Weiss E, Hoffmann R, Haas R. Helicobacter pylori vacuolating cytotoxin inhibits T lymphocyte activation. Science. 2003;301:1099-1102.

[23] Cover TL, Blaser MJ. Purification and characterization of the vacuolating toxin from Helicobacter pylori. J Biol Chem. 1992;267:10570-10575.

[24] Atherton JC, Cao P, Peek RM Jr, Tummuru MK, Blaser MJ, Cover TL. Mosaicism in vacuolating cytotoxin alleles of Helicobacter pyloriAssociation of specific vacA types with cytotoxin production and peptic ulceration.

[25] Ogiwara H, Graham DY, Yamaoka Y. vacA i-region subtyping. Gastroenterology. 2008;134:1267.

[26] Ogiwara H, Sugimoto M, Ohno T, Vilaichone RK, Mahachai V, Graham DY, Yamaoka Y.Role of deletion located between the intermediate and middle regions of the Helicobacter pylori vacA gene in cases of gastroduodenal diseases. J Clin Microbiol. 2009;47:3493-3500.

[27] Yamaoka Y, Kita M, Kodama T, Imamura S, Ohno T, Sawai N, Ishimaru A, Imanishi J, Graham DY. Helicobacter pylori infection in mice: Role of outer membrane proteins in colonization and inflammation. Gastroenterology. 2002;123:1992-2004.

[28] Lu H, Hsu PI, Graham DY, Yamaoka Y. Duodenal ulcer promoting gene of Helicobacter pylori. Gastroenterology. 2005;128:833-848.

[29] Douraghi M, Mohammadi M, Oghalaie A, Abdirad A, Mohagheghi MA, Hosseini ME, Zeraati H, Ghasemi A, Esmaieli M, Mohajerani N. dupA as a risk determinant in Helicobacter pylori infection. J Med Microbiol. 2008;57:554-562. 
[30] Nguyen LT, Uchida T, Tsukamoto Y, Kuroda A, Okimoto T, Kodama M, Murakami $\mathrm{K}$, Fujioka T, Moriyama M.Helicobacter pylori dupA gene is not associated with clinical outcomes in the Japanese population. Clin Microbiol Infect. 2010;16:1264-1269.

[31] Falush D, Wirth T, Linz B, Pritchard JK, Stephens M, Kidd M, Blaser MJ, Graham DY, Vacher S, Perez-Perez GI, Yamaoka Y, Mégraud F, Otto K, Reichard U, Katzowitsch E, Wang X, Achtman M, Suerbaum S.Traces of human migrations in Helicobacter pylori populations. Science 2003;299: 1582-1585.

[32] El-Omar EM, Carrington M, Chow WH, McColl KE, Bream JH, Young HA, Herrera J, Lissowska J, Yuan CC, Rothman N, Lanyon G, Martin M, Fraumeni JF, Jr, Rabkin CS. Interleukin-1 polymorphisms associated with increased risk of gastric cancer. Nature. 2000;404:398-402.

[33] El-Omar EM, Rabkin CS, Gammon MD, Vaughan TL, Risch HA, Schoenberg JB, Stanford JL, Mayne ST, Goedert J, Blot WJ, Fraumeni JF, Jr, Chow WH. Increased risk of noncardia gastric cancer associated with proinflammatory cytokine gene polymorphisms. Gastroenterology 2003;124:1193-201.

[34] Figueiredo C, Machado JC, Pharoah P, Seruca R, Sousa S, Carvalho R, Capelinha AF, Quint W, Caldas C, van Doorn LJ, Carneiro F, Sobrinho-Simoes M. Helicobacter pylori and interleukin 1 genotyping: an opportunity to identify high-risk individuals for gastric carcinoma. J Natl Cancer Inst 2002;94:1680-7

[35] Persson C, Canedo P, Machado JC, El-Omar EM, Forman D. Polymorphisms in Inflammatory Response Genes and Their Association With Gastric Cancer: A HuGE Systematic Review and Meta-Analyses. Am J Epidemiol. 2011 February 1; 173(3): 259-270.

[36] Wang P, Xia HH, Zhang JY, Dai LP, Xu XQ, Wang KJ.Association of interleukin-1 gene polymorphisms with gastric cancer: a meta-analysis. Int J Cancer 2007;120(3): $552-562$.

[37] Camargo MC, Mera R, Correa P, Peek RM Jr, Fontham ET, Goodman KJ, Piazuelo $\mathrm{MB}$, Sicinschi L, Zabaleta J, Schneider BG.Interleukin-1 $\beta$ and interleukin-1 receptor antagonist gene polymorphisms and gastric cancer: a meta-analysis. Cancer Epidemiol Biomarkers Prev 2006;15(9):1674-1687

[38] Kamangar F, Cheng C, Abnet CC, Rabkin CS.Interleukin-1B polymorphisms and gastric cancer risk - a meta-analysis. Cancer Epidemiol Biomarkers Prev 2006;15(10): 1920-1928.

[39] Loh M, Koh KX, Yeo BH, Song CM, Chia KS, Zhu F, Yeoh KG, Hill J, Iacopetta B, Soong R.Meta-analysis of genetic polymorphisms and gastric cancer risk: variability in associations according to race. Eur J Cancer 2009;45(14):2562-2568.

[40] Gorouhi F, Islami F, Bahrami H, Kamangar F.Tumour-necrosis factor-A polymorphisms and gastric cancer risk: a meta-analysis. Br J Cancer 2008;98(8):1443-1451. 
[41] Zhang J, Dou C, Song Y, et al. Polymorphisms of tumor necrosis factor-alpha are associated with increased susceptibility to gastric cancer: a meta-analysis. J Hum Genet 2008;53(6):479-489.

[42] Kamangar F, Abnet CC, Hutchinson AA, Newschaffer CJ, Helzlsouer K, Shugart YY, Pietinen P, Dawsey SM, Albanes D, Virtamo J, Taylor PR. Polymorphisms in inflammation-related genes and risk of gastric cancer (Finland) Cancer Causes Control 2006;17:117-25.

[43] Canedo P, Castanheira-Vale AJ, Lunet N, Pereira F, Figueiredo C, Gioia-Patricola L, Canzian F, Moreira H, Suriano G, Barros H, Carneiro F, Seruca R, Machado JC. The interleukin-8-251*T/*A polymorphism is not associated with risk for gastric carcinoma development in a Portuguese population. Eur J Cancer Prev 2008;17:28-32.

[44] Hold GL, Rabkin CS, Chow WH, Smith MG, Gammon MD, Risch HA, Vaughan TL, McColl KE, Lissowska J, Zatonski W, Schoenberg JB, Blot WJ, Mowat NA, Fraumeni JF, Jr, El-Omar EM. A functional polymorphism of toll-like receptor 4 gene increases risk of gastric carcinoma and its precursors. Gastroenterology 2007;132:905-12.

[45] Arbour NC, Lorenz E, Schutte BC, Zabner J, Kline JN, Jones M, Frees K, Watt JL, Schwartz DA. TLR4 mutations are associated with endotoxin hyporesponsiveness in humans. Nat Genet2000; 25: 187-191

[46] Gao L, Nieters A, Brenner H. Cell proliferation-related genetic polymorphisms and gastric cancer risk: systematic review and meta-analysis. Eur J Hum Genet. 2009;17:1658-67.

[47] Liao SY, Zeng ZR, Leung WK, Zhou SZ, Chen B, Sung JJ, Hu PJ.Peroxisome proliferator-activated receptor-gamma Pro12Ala polymorphism, Helicobacter pylori infection and non-cardia gastric carcinoma in Chinese. Aliment Pharmacol Ther. 2006;23:289294.

[48] Prasad KN, Saxena A, Ghoshal UC, Bhagat MR, Krishnani N. Analysis of Pro12Ala PPAR gamma polymorphism and Helicobacter pylori infection in gastric adenocarcinoma and peptic ulcer disease. Ann Oncol 2008;19:1299-1303

[49] Hamai Y, Matsumura S, Matsusaki K, K, Kitadai Y, Yoshida K, Yamaguchi Y, Imai K, Nakachi K, Toge T, Yasui W. A single nucleotide polymorphism in the 50 untranslated region of the EGF gene is associated with occurrence and malignant progression of gastric cancer. Pathobiology 2005;72: 133 - 138.

[50] Jin G, Wang L, Chen W, Hu Z, Zhou Y, Tan Y, Wang J, Hua Z, Ding W, Shen J, Zhang Z, Wang X, Xu Y, Shen H. Variant alleles of TGFB1 and TGFBR2 are associated with a decreased risk of gastric cancer in a Chinese population.Int J Cancer 2007;120: 1330 - 1335 .

[51] Zhang ZW, Newcomb PV, Moorghen M Zhang ZW, Newcomb PV, Moorghen M, Gupta J, Feakins R, Savage P, Hollowood A, Alderson D, Holly JM.Insulin-like growth factor binding protein-3: relationship to the development of gastric pre-ma- 
lignancy and gastric adenocarcinoma (United Kingdom). Cancer Causes Control 2004;15:211 - 218 .

[52] Chen W, Wang L, Ke Jin G, Tan Y, Zhou Y, Hu Z, Ma H, Wang J, Hua Z, Ding W, Shen J, Xu Y, Shen H. The role of IGFBP3 functional polymorphisms in the risk of gastric cancer in a high-risk Chinese population.Eur J Cancer Prev 2008;17: 82 - 87.

[53] Loh JT, Friedman DB, Piazuelo MB, Bravo LE, Wilson KT, Peek RM Jr,Correa P, Cover TL. Analysis of Helicobacter pylori cagA promoter elements required for salt-induced upregulation of CagA expression. Infect Immun 2012;80:3094-106.

[54] Blanca Piazuelo M, Epplein M, Correa P. Gastric cancer: An infectious disease. Infect Dis Clin North Am 2010; 24(4): 853-869

[55] Fox JG, Dangler CA, Taylor NS, King A, Koh TJ, Wang TC. High-salt diet induces gastric epithelial hyperplasia and parietal cell loss, and enhances Helicobacter pylori colonization in C57BL/6 mice. Cancer Res 1999;59(19):4823-8.

[56] Yamaguchi N, Kakizoe T. Synergistic interaction between Helicobacter pylori gastritis and diet in gastric cancer. Lancet Oncol 2001;2(2):88-94.

[57] Ladeiras-Lopes R, Pereira AK, Nogueira A, Pinheiro-Torres T, Pinto I, Santos-Pereira R, Lunet N. Smoking and gastric cancer: systematic review and meta-analysis of cohort studies. Cancer Causes Control 2008; 19:689 - 701.

[58] Koizumi Y, Tsubono Y, Nakaya N, Kuriyama S, Shibuya D, Matsuoka H, Tsuji I. Cigarette smoking and the risk of gastric cancer: a pooled analysis of two prospective studies in Japan. Int J Cancer 2004; 112: 1049 - 1055.

[59] Sjodahl K, Lu Y, Nilsen TI, Ye W, Hveem K, Vatten L, Lagergren J. Smoking and alcohol dinking in relation to risk of gastric cancer: a population-based,prospective cohort study. Int J Cancer 2007; 120: 128 - 132.

[60] Moy KA, Fan Y, Wang R, Gao YT, Yu MC, Yuan JM. Alcohol and tobacco use in relation to gastric cancer: a prospective study of men in Shanghai,China. Cancer Epidemiol Biomarkers Prev 2010; 19: 2287 - 2297.

[61] Duan L, Wu AH, Sullivan-Halley J, Berstein L. Passive smoking and risk of oesophageal and gastric adenocarcinomas. Br J Cancer 2009;100: 1483 - 1485

[62] Algra AM, Rothwell PM. Effects of regular aspirin on long-term cancer incidence and metastasis: a systematic comparison of evidence from observational studies versus randomised trials. Lancet Oncol 2012;13(5):518-27.

[63] Bosetti C, Rosato V, Gallus S, Cuzick J, La Vecchia C. Aspirin and cancer risk: a quantitative review to 2011. Ann Oncol 2012;23(6):1403-15.

[64] Wong BC, Zhang L, Ma JL, Pan KF, Li JY, Shen L, Liu WD, Feng GS, Zhang XD, Li J, Lu AP, Xia HH, Lam S, You WC. Effects of selective COX-2 inhibitor and Helicobacterpylori eradication on precancerous gastric lesions. Gut 2012;61(6):812-8. 
[65] Tian W, Zhao Y, Liu S, Li X. Meta-analysis on the relationship between nonsteroidal anti-inflammatory drug use and gastric cancer. Eur J Cancer Prev. 2010 ;19(4):288-98

[66] Conteduca V, Sansonno D, Ingravallo G, Marangi S, Russi S, Lauletta G, Dammacco F. Barrett's esophagus and esophageal cancer: an overview. Int J Oncol 2012; 41:414-424.

[67] Fuccio L, Eusebi LH, Bazzoli F. Gastric cancer, Helicobacterpylori infection and other risk factors. World J Gastrointest Oncol 2010; 2:342-347.

[68] Correa P, Haenszel W, Cuello C, Tannenbaum S, Archer M. A model for gastric cancer epidemiology. Lancet 1975; 2: 58-60.

[69] Wong BC, Lam SK, Wong WM, Chen JS, Zheng TT, Feng RE, Lai KC, Hu WH, Yuen ST, Leung SY, Fong DY, Ho J, Ching CK. Helicobacterpylori eradication to prevent gastric cancer in a high-risk region of China: a randomized controlled trial. JAMA 2004;291:187-194.

[70] Leung WK, Lin SR, Ching JY, To KF, Ng EK, Chan FK, Lau JY, Sung JJ. Factors predicting progression of gastric intestinal metaplasia: results of a randomised trial on Helicobacterpylori eradication.Gut 2004;53(9):1244-1249

[71] Correa P, Fontham ET, Bravo JC, Bravo LE, Ruiz B, Zarama G, Realpe JL, Malcom GT, Li D, Johnson WD, Mera R. Chemoprevention of gastric dysplasia: randomized trial of antioxidant supplements and anti-Helicobacterpylori therapy. J Natl Cancer Inst 2000;6;92:1881-1888.

[72] Mera R, Fontham ET, Bravo LE, Bravo JC, Piazuelo MB, Camargo MC, Correa P. Long term follow up of patients treated for Helicobacterpylori infection. Gut 2005;54(11):15361540 .

[73] You WC, Brown LM, Zhang L, Li JY, Jin ML, Chang YS, Ma JL, Pan KF, Liu WD, Hu Y, Crystal-Mansour S, Pee D, Blot WJ, Fraumeni JF Jr, Xu GW, Gail MH. Randomized double-blind factorial trial of three treatments to reduce the prevalence of precancerous gastric lesions. J Natl Cancer Inst 2006; 98:974-983.

[74] Ma JL, Zhang L, Brown LM, Li JY, Shen L, Pan KF, Liu WD, Hu Y, Han ZX, CrystalMansour S, Pee D, Blot WJ, Fraumeni JF Jr, You WC, Gail MH. Fifteen-year effects of Helicobacterpylori, garlic, and vitamin treatments on gastric cancer incidence and mortality. J Natl Cancer Inst 2012;104:488-492.

[75] Fukase K, Kato M, Kikuchi S, Inoue K, Uemura N, Okamoto S, Terao S, Amagai K, Hayashi S, Asaka M; Japan Gast Study Group.Effect of eradication of Helicobacterpylori on incidence of metachronous gastric carcinoma after endoscopic resection of early gastric cancer: an open-label, randomised controlled trial. Lancet 2008;372:392-397.

[76] Lee YC, Chen TH, Chiu HM, Shun CT, Chiang H, Liu TY, Wu MS, Lin JT. The benefit of mass eradication of Helicobacterpylori infection: a community-based study of gastric cancer prevention. Gut 2013;62:676-82 
[77] El-Omar EM. Role of host genes in sporadic gastric cancer. Best Pract Res Clin Gastroenterol. 2006;20:675-86. 
